\title{
Correlation of Anthropometric Features with Peroneus Longus and Hamstring Tendons Graft Size for $A C L$ reconstruction
}

\author{
Aditya Fuad Robby Triangga ${ }^{1}$, Luthfi Hidayat ${ }^{1}$, Andi Karsapin $\mathrm{T}^{1}$, Zikrina A. Lanodiyu ${ }^{1}$, Rahadyan Magetsari ${ }^{1}$
}

${ }^{1}$ Department of Orthopaedics and Traumatology, Dr. Sardjito General Hospital/ Faculty of Medicine, Universitas Gadjah Mada, Yogyakarta, Indonesia

\section{ABSTRACT}

Background: Reconstruction of the anterior cruciate ligament $(A C L)$ is a commonly performed surgical procedure in recent years. Surgeons have to consider several factors including patient's anthropometric variables to harvest the best graft. The hamstring tendon has its' limitation, such as the tendon graft size deemed unfit especially for people of small statures. The peroneus longus tendon is a relatively new choice compared to hamstring. This study was conducted to know the correlation between anthropometric features with graft parameters or graft size in patients who underwent $\mathrm{ACL}$ reconstruction using peroneus longus and hamstring tendons.

Materials and Methods: This cross-sectional study was performed in patients who underwent ACL reconstruction using peroneus longus or hamstring tendon autografts. We evaluated their anthropometric variables (age, gender, body mass index (BMI), height and weight) and correlated them with the graft diameter obtained during surgery. Post-operative results were assessed with Karlsson and Peterson Scoring System which represent the ankle function.

Results: Twenty-three non-athletic patients underwent $\mathrm{ACL}$ reconstruction surgery. Patients with hamstring graft have the average height of $170 \mathrm{~cm}$ and $163.6 \mathrm{~cm}$ for the peroneal graft group. The average body weight of the hamstring graft group was $72.917 \mathrm{~kg}$ and the peroneal graft group was $68.82 \mathrm{~kg}$. The measured BMI of the hamstring graft group was $25.2 \mathrm{~kg} / \mathrm{m} 2$ and $7.833 \mathrm{~mm}$ of graft diameter in average, with $25.5 \mathrm{~kg} / \mathrm{m}^{2}$ and $7.636 \mathrm{~mm}$ respectively for the peroneus graft group. There were strong positive correlations between weight and BMI with hamstring tendon graft diameter, but negative weak correlations with peroneus tendon graft diameter.

Conclusion: We found that body weight and BMI correlate with the diameter of both peroneus and hamstring tendon grafts. Both autografts showed equally good functional results.

Keywords: ACL reconstruction, Hamstring tendon, Peroneus longus tendon, autograft, BMI Level of Evidence: IV

\section{cc) (†) (?)}

This is an open access article under the $\underline{\mathrm{CC}-\mathrm{BY}-\mathrm{SA}}$ license. Article history:

Submission

Revision

Accepted
: December $18^{\text {th }}, 2020$

: December 31 ${ }^{\text {th }}, 2020$

: January $13^{\text {th }}, 2021$
Corresponding Author:

Aditya Fuad Robby Triangga, MD

Department of Orthopaedics and Traumatology, Dr.

Sardjito General Hospital / Universitas Gadjah Mada. Jalan

Kesehatan, No. 1, Sekip, Yogyakarta 56281, Indonesia,

Mobile : +62 812 10355167,

Phone : +62 274515054 ,

Fax : +62 274553143 ,

Email :dr.robby_triangga@yahoo.com 


\section{Introduction}

Reconstruction of the knee anterior cruciate ligament $(A C L)$ is performed in order to restore its function after an injury. Currently, this procedure is performed under arthroscopy, and it can be done with different types of graft. However, there is no consensus about the best graft choice to replace the injured ACL. One of the choices, patella tendon grafts tend to cause pain on the anterior of the knee, especially when kneeling, with added chances of developing osteoarthritis ${ }^{1}$. Hamstring tendons being the second option, are popular because it provides better strength than patellar tendon-bone complex while having less morbidity caused by the graft harvesting procedure ${ }^{2}$. At the same time, using them may reduce the hamstring muscle strength despite being needed to reduce anterior drawer forces afflicting the newly replaced $\mathrm{ACL}^{3}$. To further add to these challenges, using hamstring tendon may pose a reliability problem mainly because of the varying diameters between individuals. This may lead to inefficient performance or even graft failure ${ }^{2}$.

But recently the peroneus longus tendon has shown potential as a better substitute because of its tensile strength and the potential of regeneration after being used post replacement ${ }^{3,4}$. Furthermore, it is easily harvested and the procedure itself leaves minimal complications for the patient, aside from post-operation ankle joint functionality ${ }^{5,6,7}$.

This study was done under the purpose of finding the relationship between a certain individual's body measurements and the size of hamstring and peroneus longus tendon grafts, in addition to evaluations of the ankle joint performance in the peroneus graft patient group. The data obtained will be further used to determine if peroneus longus tendon is a suitable candidate for repairing $A C L$ tendon injuries in clinical practice.

Material and Methods

This was a cross-sectional study with an analytical approach conducted by looking at the diameter of the autografts and comparing them to the andromorphic data measured beforehand. The data were then being analyzed using Pearson correlation tests.

The subjects of this study were men and women with the diagnosis of $A C L$ rupture who were eligible for receiving $A C L$ reconstruction using autografts. The subjects came to the Orthopedic and Traumatology Polyclinic of RSUP Dr. Sardjito, then a physical examination identified the patient's anthropometric variables which were their age, gender, height and weight measured by the research team followed by operative action which was done at RSUP Dr. Sardjito Hospital, Yogyakarta, Indonesia.

To harvest the grafts, an anteromedial incision was made to expose the sartorius fascia of the hamstring group patients and a $3-\mathrm{cm}$ incision behind the lateral malleolus with the knee under full extended condition for peroneus longus graft. In the hamstring tendon group, the grafts were harvested from semitendinosus and gracilis tendon. The extracted grafts were then measured using Smith and Nephew sizing cylinder for graft diameter documentation. If the measured diameter did not exceed a minimum of $8.5 \mathrm{~mm}$, an additional strand was added to ensure graft survival without following any specific algorithm. Graft length were not documented. After independently preparing the implantation tunnels, we utilized a button for femoral side fixation (XO Button ${ }^{\circledR}$, Conmed $($ ) , USA) and a screw for the tibial side (Bioscrew ${ }^{\circledR}$, Conmed $\subset$, USA). Prior to fixation, we made sure to properly tension the grafts with a graft tensioner. The patient's lower extremity functions and healing time were then recorded as additional data.

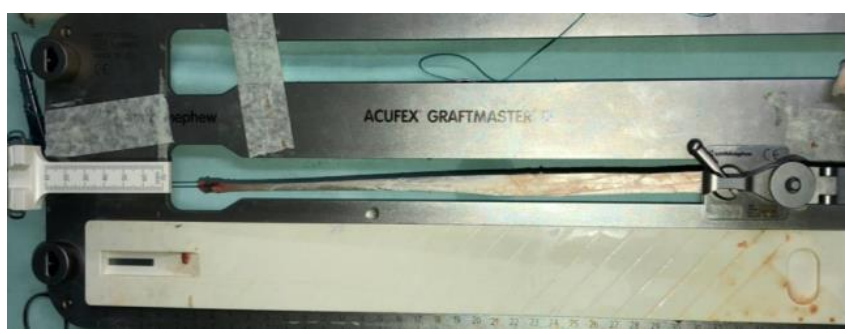

Figure 1. Measurement of the graft 


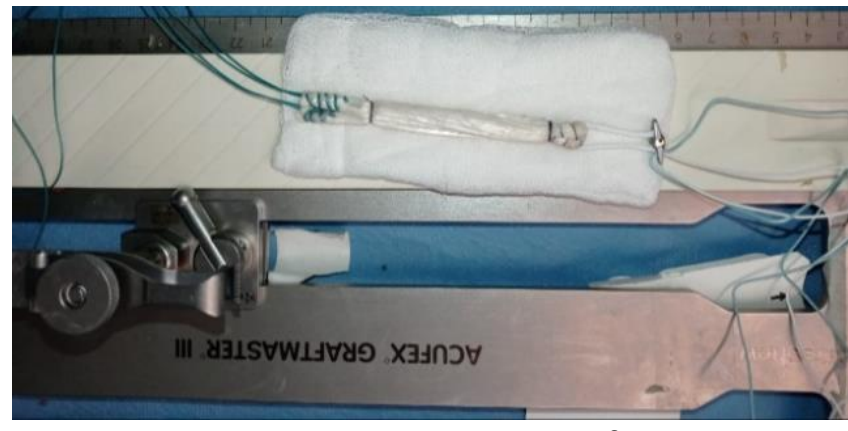

Figure 2. Finished Graft

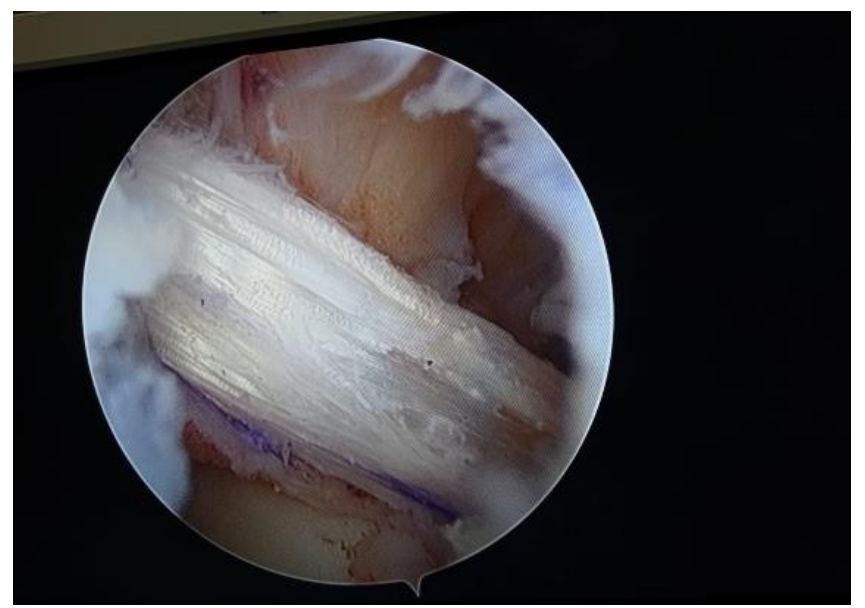

Figure 3. Completed graft procedure

\section{Results}

This study involved a total of 23 subjects which consisted of 12 people in the hamstring graft group and 11 in the peroneus group. In the hamstring graft group, 11 of the participants were males and there was 1 female. In the peroneus group, there were 5 females and 6 males. In addition to the anthropometric measurements, participants in the peroneus graft group were also evaluated using the Karlson and Peterson ankle scoring system and categorized based on their performance.

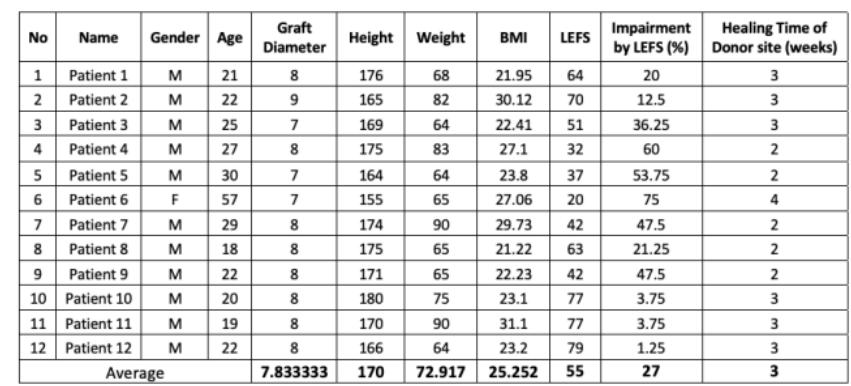

Table 1. Anthropometric data of hamstring graft group
With the average height of $170 \mathrm{~cm}$, the tallest participant measured in this group was $180 \mathrm{~cm}$ and the shortest was $155 \mathrm{~cm}$. The average diameter of the graft made from the hamstring group was $7.833 \mathrm{~mm}$. The minimum size of the diameter was $7 \mathrm{~mm}$ and the largest diameter was $9 \mathrm{~mm}$. The heaviest participant measured in this group was $90 \mathrm{~kg}$ and the lightest was $64 \mathrm{~kg}$, with the average weight of $73.714 \mathrm{~kg}$. After the calculations, the BMI from this group ranged from 21.22 to 31.1 , with 25.252 being the average BMI. A lower extremity function value of 70 was recorded as the highest (1.25\% impairment) and 20 as the lowest (75\% impairment), making the average LEF score of 55 ( $27 \%$ impairment). The donor site wounds recovered within 2-4 weeks post-surgery.

\begin{tabular}{|c|c|c|c|c|c|c|c|c|c|c|c|c|}
\hline \multirow{4}{*}{ 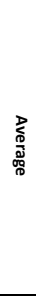 } & 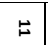 & $\stackrel{b}{ }$ & 0 & $\infty$ & $v$ & $a$ & u & $\rightarrow$ & $\omega$ & $\sim$ & $r$ & z \\
\hline & 总 & 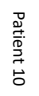 & 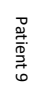 & 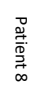 & 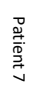 & 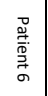 & 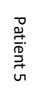 & 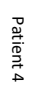 & 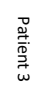 & 总 & 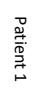 & 总 \\
\hline & 3 & 3 & 3 & 3 & $\pi$ & $\pi$ & 3 & $\pi$ & $\pi$ & 3 & $\pi$ & 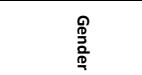 \\
\hline & $\tilde{\sigma}$ & $\tilde{f}$ & $\widetilde{\sim}$ & $\tilde{\sim}$ & $\approx$ & $\bullet$ & $\tilde{\sim}$ & ปั & D & $\checkmark$ & $\vec{\infty}$ & 品 \\
\hline 啇 & $\infty$ & $\infty$ & $\infty$ & $\infty$ & $v$ & $\checkmark$ & $\checkmark$ & $\infty$ & $\infty$ & $\infty$ & $\checkmark$ & 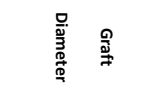 \\
\hline 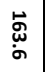 & 泀 & 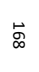 & $\stackrel{\ddot{\alpha}}{\alpha}$ & 岕 & 㟧 & $\vec{\sigma}$ & 苟 & 岁 & 嵳 & 志 & $\vec{v}$ & 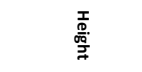 \\
\hline 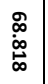 & $\infty$ & $\stackrel{\infty}{\circ}$ & $\stackrel{\infty}{\dddot{1}}$ & \& & $\stackrel{\omega}{\omega}$ & $\vec{v}$ & g & g & 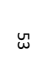 & Љ & $\stackrel{\infty}{\circ}$ & 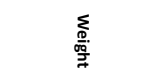 \\
\hline $\begin{array}{l}\tilde{y} \\
\tilde{u} \\
6\end{array}$ & $\stackrel{\omega}{\stackrel{\omega}{\sim}}$ & $\underset{\tilde{w}}{\tilde{w}}$ & $\stackrel{\tilde{N}}{\sim}$ & $\stackrel{\tilde{i}}{\mathrm{u}}^{\tilde{N}}$ & 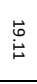 & $\begin{array}{l}\tilde{N} \\
\mathscr{0} \\
0\end{array}$ & $\begin{array}{c}\tilde{w} \\
\substack{\infty \\
\infty \\
\infty}\end{array}$ & $\stackrel{\widetilde{\Xi}}{\tilde{E}}$ & $\stackrel{\tilde{F}}{i n}$ & $\stackrel{\widetilde{N}}{\sim}$ & 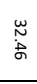 & $\stackrel{\underline{w}}{\underline{3}}$ \\
\hline & ๑ & $\stackrel{\infty}{\sim}$ & $\stackrel{\infty}{\sim}$ & $\stackrel{\infty}{\circ}$ & a & $\stackrel{\sim}{\sim}$ & 哭 & ↔ & 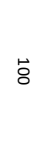 & $\stackrel{\sim}{\sim}$ & $\sim$ & 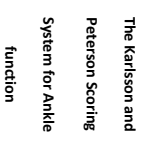 \\
\hline & $\omega$ & $\omega$ & $\sim$ & $\sim$ & $N$ & $\omega$ & $\leftrightarrow$ & $\omega$ & $r$ & $\omega$ & $\omega$ & 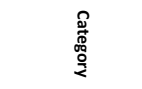 \\
\hline$\checkmark$ & $\Xi$ & $\ddot{A}$ & $\Xi$ & $\check{a}$ & $\tilde{A}$ & $\stackrel{w}{\sim}$ & $\stackrel{\sim}{\sim}$ & \pm & $\widetilde{\omega}$ & $\Phi$ & \& & 霄 \\
\hline$\approx$ & $\begin{array}{l}\tilde{\tilde{N}} \\
\tilde{\tilde{N}}\end{array}$ & ì & 岕 & ì & ১े & 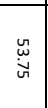 & $\underset{\sim}{\omega}$ & 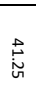 & $\stackrel{\infty}{\tilde{v}}$ & $\tilde{\Sigma}$ & $\tilde{o}$ & 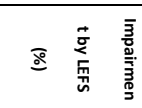 \\
\hline
\end{tabular}

Table 2. Anthropometric data of peroneus longus graft group 
From the second table, the graft diameter from the peroneus group ranged from $7 \mathrm{~mm}$ to 8 $\mathrm{mm}$ with the average of $7.636 \mathrm{~mm}$. The tallest participant measured in the group was $180 \mathrm{~cm}$ and $150 \mathrm{~cm}$ were the shortest, thus making the average height as $163 / 6 \mathrm{~cm}$. $86 \mathrm{~kg}$ was the heaviest and $43 \mathrm{~kg}$ was the lightest weight measured. The BMI calculated in the peroneus graft group was 19.11 at the lowest and 32.46 as the highest, with the average of 25.579. The best score recorded for the peroneus group's lower extremity function was 74 (7.50\% impairment) and the worst was 24 (70\% impairment). The average score for this group's function was 57 (27\% impairment). Categorized from Karlsson and Peterson scoring system, it can be seen that 2 of the patients were in the excellent category and 3 patients were in the good category. Except for 1 patient categorized with poor ankle function, the remaining 5 patients were in the fair category.

\begin{tabular}{|c|c|c|c|c|c|}
\hline & & Diameter graft & Height & Weight & BMI \\
\hline \multirow[t]{5}{*}{ Diameter graft } & Pearson Correlation & 1 & 0.396 & 0.735 & 0.586 \\
\hline & Sig. (2-tailed) & & 0.38 & 0.6 & 0.167 \\
\hline & $r$ & & 0.394 & 0.520 & 0.324 \\
\hline & $\mathrm{R}^{2}$ & & 0.155 & 0.270 & 0.105 \\
\hline & $\mathrm{N}$ & 7 & 7 & 7 & 7 \\
\hline \multirow[t]{3}{*}{ Height } & Pearson Correlation & 0.396 & 1 & 0.473 & -0.153 \\
\hline & Sig.(2-tailed) & 0.38 & & 0.284 & 0.743 \\
\hline & $\mathrm{N}$ & 7 & 7 & 7 & 7 \\
\hline \multirow[t]{3}{*}{ Weight } & Pearson Correlation & 0.735 & 0.473 & 1 & 0.797 \\
\hline & Sig.(2-tailed) & 0.06 & 0.284 & & 0.32 \\
\hline & $\mathrm{N}$ & 7 & 7 & 7 & 7 \\
\hline \multirow[t]{3}{*}{ BMI } & Pearson Correlation & 0.586 & -0.153 & 0.797 & 1 \\
\hline & Sig.(2-tailed) & 0.167 & 0.743 & 0.032 & \\
\hline & $\mathrm{N}$ & 7 & 7 & 7 & 7 \\
\hline
\end{tabular}

Table 3. Pearson correlation between hamstring graft and patient's anthropometry.

From Table 3, the diameter of the hamstring graft showed a minor positive correlation with the patient's height $(r=0.394, p=0.396)$. A positive correlation was found between the diameter and the patient's BMI as well $(r=0.324, p=0.58)$, with the most relevant positive correlation between the diameter and the patient's weight $(r=0.520, p$ $=0.735)$.

\begin{tabular}{|c|c|c|c|c|c|}
\hline & & Diameter graft & Height & Weight & BMI \\
\hline \multirow{5}{*}{ Diameter graft } & Pearson Correlation & 1 & 0.53 & -0.259 & -0.27 \\
\hline & Sig.(2-tailed) & & 0.911 & 0.575 & 0.558 \\
\hline & $r$ & & 0.325 & 0.177 & -0.001 \\
\hline & $R^{2}$ & & 0.105 & 0.031 & 0 \\
\hline & $\mathrm{N}$ & 7 & 7 & 7 & 7 \\
\hline \multirow[t]{3}{*}{ Height } & Pearson Correlation & 0.053 & 1 & 0.462 & -0.089 \\
\hline & Sig.(2-tailed) & 0.911 & & 0.297 & 0.849 \\
\hline & $\mathrm{N}$ & 7 & 7 & 7 & 7 \\
\hline \multirow[t]{3}{*}{ Weight } & Pearson Correlation & -0.259 & 0.462 & 1 & 0.84 \\
\hline & Sig.(2-tailed) & 0.575 & 0.297 & & 0.18 \\
\hline & $\mathrm{N}$ & 7 & 7 & 7 & 7 \\
\hline \multirow[t]{3}{*}{ BMI } & Pearson Correlation & -0.27 & -0.089 & 0.84 & 1 \\
\hline & Sig.(2-tailed) & 0.558 & 0.849 & 0.18 & \\
\hline & $\mathrm{N}$ & 7 & 7 & 7 & 7 \\
\hline
\end{tabular}

Table 4. Pearson correlation between peroneus graft and patient's anthropometry.

Displayed in table 4, the peroneus graft diameter and body weight seemed to correlate negatively $(r=0.177$, $p=-0.259)$, and peroneus tendon graft diameter did not seem to significantly correlate with BMI $(r=-0.001$, $p=-0.27$ ). On the other hand, there was a strong positive correlation between the peroneus graft and the body height $(r=0.325, p=0.53)$.

\section{Discussion}

The hamstring graft diameter in our study correlated with the weight parameter the strongest $(r$ $=0.520)$. This result is supported by Stergios et. al, whose results correlate the best with weight, followed by the height and $\mathrm{BMI}^{8}$. However, Pinheiro et. al only found significant correlation with weight and height parameters ${ }^{9}$. These comparisons indicate that weight measurements might be more reliable in predicting hamstring tendon graft sizes.

The peroneus graft diameters can be predicted using individual anthropometric measurements such as weight and height. The $\mathrm{BMI}$, on the other hand, remains debatable. The most significant predictor for peroneus tendon grafts in our studies seems to be the patient's body height. This compliments Thomas' conclusion about body height being the most prominent predictor of graft diameter ${ }^{1}$. Some differences can be suspected as the research was conducted in different continents. Treme and Chiang's research concluded a noticeable difference in hamstring tendon sizes after comparing the data between Caucasian and Chinese populations ${ }^{10,11}$, while such difference may theoretically present in peroneus 
tendon length as well. Compared to another similar study, Song's data showed positive correlations between the graft diameter and the weight, height, and the patient's BMI, which compliments Thomas's conclusions instead of contradicting their findings ${ }^{1,12}$.

Most studies have conducted gender-based correlation upon the aforementioned grafts, and reported findings of different anthropometric predictors on each graft and sexes. Janssen's study shown that women tend to have smaller hamstring graft size (1:36 in men, 1:9 in women), and this result is supported by Pinheiro's data ${ }^{9,12}$. Using anthropometric factors, Stergios concluded that none of the anthropometric measurements are usable as predictors for women ${ }^{8}$. His findings are contradictory with Xie et al, who summarized that women's graft measurement correlated only to height, while men are able to have their weights and heights used as predictor ${ }^{13}$. Assessing 95 Indian population, Goyal et al made the same conclusion with Xie, stating the height as a viable means of predicting hamstring graft sizes in women, with thigh length being the predictor in men $^{15}$. Considering the previous studies, the hamstring grafts are more sizable in male patients. These findings are in accordance to Mardani-Kivi's research, further strengthening the notion of using hamstring grafts mainly for taller men ${ }^{5}$. Even though the peroneus longus graft diameters in our patient group also showed a certain degree of variance, they were more uniform in diameter, which should be favorable for some individuals. But Angthong's study showed evidence of ankle instabilities of considerable degree in both inversion and eversion, particularly in the first 12 months post-operation ${ }^{2}$. These findings are similar to Shao's research, which calculated a general decrease of $22 \%$ of inversion and eversion strength after the use of full thickness peroneal grafting albeit the lack of ankle joint instability ${ }^{16}$. Their research conflicted with Liu and Trung's study to a certain extent, since they stated that none of their patients complained of ankle joints instability after they utilized only the anterior half of the peroneus longus tendon ${ }^{6,17}$. Further research might be needed since the fundamental difference about them is how only half PLT grafts were used instead of full thickness PLT grafts ${ }^{2,6,16,17}$. Thus, it might be compulsory for patients who prefer to use this graft to undergo monitoring and rehabilitation in that period in order to reduce the morbidity.

This study has some limitations. Regarding the sample size, which was not large enough to represent the whole population, made data analysis by gender unavailable due to how little it is. Some other data of the patients such as age, job, and daily activities might be significant enough to affect the graft diameter and the recovery period as concluded in some studies. Sadly, they are failed to be documented. Another weakness is the lack of follow-up which makes the effectivity of the grafts not known in the long term. While considering the aforementioned points, the overall study helped us to further decide about grafting hamstring or peroneus longus before the operation by simply measuring the patient's anthropometry.

\section{Conclussion}

Body weight and BMI correlated directly with the diameter of both peroneus and hamstring tendon autografts. The peroneus longus tendon can be considered as eligible to be one of the viable candidates for the $\mathrm{ACL}$ reconstruction, especially among small stature patients.

\section{Compliance with Ethical Standards}

\section{Conflict of interest}

The authors declare that they have no competing interests.

\section{Ethical approval}

All procedures performed in studies involving human participants were in accordance with the ethical standards of the institutional and/or national research committee and with the 1964 Helsinki declaration and its later amendments or comparable ethical standards.

\section{Informed consent}

Informed consent was obtained from all participants. 


\section{References}

1. Thomas S, Bhattacharya R, Saltikob JB, Kramer DJ. Influence of anthropometric features on graft diameter in ACL reconstruction. Arch Orthop Trauma Surg. 2013;133:215-218.

2. Angthong C, Chernchujit B, Apivatgaroon A, Chaijenkit K, Nualon $P$, Suchao-in K. The anterior cruciate ligament reconstruction with the peroneus longus tendon: a biochemical and clinical evaluation of the donor ankle morbidity. J Med Assoc Thai. 2015;98(6):555-60.

3. Kerimoglu S, Aynaci O, Saracoglu M, Aydin H, Turhan AU. Anterior cruciate ligament reconstruction with the peroneus longus tendon. Acta Orthop Traumatol Turc 2008:42(1):38-43.

4. Phatama KY, Hidayat M, Mustamsir E, Pradana AS, Dhananjaya B, Muhammad SI. Tensile strength comparison between hamstring tendon, patellar tendon, quadriceps tendon and peroneus longus tendon: A cadaver research. Journal of Arthroscopy and Joint Surgery. 2019 May 1;6(2):114-6.

5. Mardani-Kivi $M$, Karimi-Mobarakeh $M$, Mirbolook A, Keyhani S, Saheb-Ekhtiari K, HashemiMotlagh $\mathrm{K}$, et al Predicting the hamstring tendon diameter using anthropometric parameters. Arch Bone Jt Surg. 2016;4(4):314-317.

6. Liu CT, Lu YC, Huang $\mathrm{CH}$. Half-peroneus-longus-tendon graft augmentation for unqualified hamstring tendon graft of anterior cruciate ligament reconstruction. J Orthop Sci 2015;20:854860.

7. Rhatomy S, Asikin AIZ, Wardani AE, Rukmoyo T, Lumban-Gaol I, Budhiparama NC. Peroneus longus autograft can be recommended as a superior graft to hamstring tendon in single-bundle $\mathrm{ACL}$ reconstruction. European Society of Sports Traumatology, Knee Surgery, Arthroscopy. 2019;27:3552-3559.

8. Papastergiou SG, Konstantinidis GA, Natsis K, Papathanasiou E, Koukoulias N, Papadopoulos AG. Adequacy of semitendinosus tendon alone for anterior cruciate ligament reconstruction graft and prediction of hamstring graft size by evaluating simple anthropometric parameters. Anat Res Int. 2012;2012:424158.

9. Pinheiro LFJr, de Andrade MA, Teixeira LE, Bicalho LAL, Lemos WG, Azeredo SAC, et al Intraoperative four stranded hamstring tendon graft diameter evaluation. Knee Surg Sports Traumatol Arthrosc 2011;19:811-5.
10. Treme G, Diduch DR, Billante MJ, Miller MD, Hart JM. Hamstring graft size prediction: a prospective clinical evaluation. Am J Sports Med. 2008. 36(11):2204-2209.

11. Chiang ER, Ma HL, Wang ST, Hung SC, Liu CL, Chen TH. Hamstring graft sizes differ between Chinese and Caucasians. Knee Surg Sports Traumatol Arthrosc. 2012;20(5):916-921.

12. Song $X, L i Q, W u Z, X u Q$, Chen $D$, Jiang $Q$. Predicting the graft diameter of the peroneus longus tendon for anterior cruciate ligament reconstruction. Medicine. $2018 \mathrm{Nov}$;97(44).

13. Janssen RPA, van der Velden MJF, van den Besselaar M, Reijman M. Prediction of length and diameter of hamstring tendon autografts for knee ligament surgery in Caucasians. Knee Surgery, Sports Traumatology, Arthroscopy, 2015;25(4):1199-1204.

14. Xie $G$, Huangfu X, Zhao J. Prediction of the graft size of 4-stranded semitendinosus tendon and 4stranded gracilis tendon for anterior cruciate ligament reconstruction: a Chinese Han patient study. Am J Sports Med. 2012;40(5):1161-1166.

15. Goyal T, Paul S, Das L, Choudhury AK. Correlation between anthropometric measurements and activity level on length and diameter of semitendinosus tendon autograft in knee ligament surgery: A prospective observational study. SICOT-J. 2020;6(23).

16. Shao $X$, Shi LL, Bluman EM, Wang S, Xu X, Chen $X$, et al Satisfactory functional and MRI outcomes at the foot and ankle following harvesting of full thickness peroneus longus tendon graft. Bone Joint J 2020;102$\mathrm{B}(2): 205-211$.

17. Trung DT, Manh SL, Thanh LN, Dinh TC, Dinh TC. Preliminary result of arthroscopic anterior cruciate ligament reconstruction using anterior half of peroneus longus tendon autograft. Open Access Macedonian Journal of Medical Sciences. 2019 Dec 30; 7(24):4351-4356. 